\title{
Investigation of Critical Factors that Perturb Business-IT Alignment in Organizations
}

\author{
Muhammad Asif Khan \\ Department of Information Systems \\ College of Computer Science and Engineering \\ Taibah University, Madina al Munawwara, Saudi Arabia
}

\begin{abstract}
Business executives around the globe have recognised the significance of information technology (IT) and started adopting IT in their business processes. Firms always invest in adopting latest technologies in order to comply with the customer requirements despite of heavy investment companies are unable to avail optimum benefits from the underpinning technologies. Consequently IT does not support business the way it should have been and hence a misalignment between business and IT is created. In the current study various factors in a Saudi financial institution have been discussed and assessed that perturb alignments in both the entities. In the research study questionnaire approach has been used which is an effective tool to collect qualitative data. Finally, some recommendations have been suggested to bring business and IT into an alignment.
\end{abstract}

Keywords-Alignment; Business-it gap; Organizational factors; Strategic alignment, Critical factors

\section{INTRODUCTION}

In today's business world business executives recognise the importance and value of information technology (IT). The rapid growth in technologies has forced firms to adopt technologies in order to automate business processes and fulfill customer demands. Despite of spending heavy amount on acquiring technologies businesses are unable to avail optimum benefits from the technologies. Many researchers and practitioners have discussed various reasons and all of them agree that there is a misalignment between business and underpinning technologies.

Researchers and practitioners have been working in figuring out the reasons for misalignment for a long time and developed various models. A strategic alignment model [1] describes how business and IT strategies and organizational infrastructure assist in achieving alignment between business and IT. In the model, four domains were discussed that are interlinked with each other and one domain impacts on other. The four domains were expanded into 12 dimensions in a model proposed by [2]. Some informal aspects of alignment have been discussed in a model proposed by [3] which was not indicated earlier in the four domains model. In an empirical study [4] barriers have been listed that help to achieve alignment between business and IT. Other studies have discovered different organizational factors including communication, top management support and commitment, organization structure, training, organization culture, project management [5][6][7] and governance of IT [8]. In a study of alignment [9], described pattern of alignment is based on three factors, namely, (1) complexity, (2) co-dependency, and (3) conflicts. In order to bring business and technology into alignment a co-evolutionary framework was developed by [23] in which different layers in organizations were discussed. The alignment between business and IT is important in order to maximise the value that technology creates in business [24]. When business is separated from IT organizations they cannot extract the value of IT and consequently performance is badly affected [26]. As the alignment is discussed at functional and strategic levels, [25] an approach is proposed to align business processes and supporting software at functional level. A coevolutionary theory using complexity theory presents sustainable IS alignment which occurs only when organization's IS co-evolves with organization [10]. A framework presented by [35] explains the dynamic business requirements for co-evolution of business and IT. Another study states that there is a co-alignment between service innovation and IT, i.e. internally there should be consistency between business processes and required technologies [11]. In a study, antecedents of business and IT were studies and it was found that sharing of domain knowledge, confidence in IT and planning in organizations were the factors for alignment in business and IT [12]. In order to achieve business goals organizations consider business-IT alignment as a major factor and IT as an enabler [30]. It is important to understand in organizations, business and IT executives who have strengths in respective areas always design strategies in isolation and in turn alignment occurs. A model has been developed by [31] that provide an environment to develop a generic strategy which shows the dependencies of business and IT. The dependency of elements in both business and IT are more transparent and allows influencing each other. Business-IT alignment within business goals and strategy is a key to a success in a company [36].

\section{ORGANIZATIONAL CRITICAL FACTORS}

Traditionally, organizations have been striving to design and develop effective strategies to bring business and IT into alignment. Nevertheless, despite of developed strategies and huge investment, organizations are unable to avail optimum benefits of the investment. It appears that there are other factors also which contribute in business and IT alignment. Researchers and practitioners have described different factors that ascertain value of IT and business on one hand (and perturb the alignment between) and IT on the other [20][21]. Below are the most stated critical factors that affect alignment between business and IT. 


\section{A. Structure}

In order to keep the control over computing resources and information, organizations tend to centralise resources. The centralisation of information causes delay in making right decision on right time and/or information arrives late to the targeted audience. Organisation structure becomes a perturbing factor when it comes to make strategic decisions for implementation of business and IT. If organizational structure is hierarchical then information flow at every level could help in readily decision making and implementation in organization. This may create efficacy and impact on value of business and IT [22]. In a centralised structure the commitment of top management is crucial as it is essential for business-IT alignment [32]. Also it is important for business executives to be knowledgeable in IT in order to evaluate investment in IT to realise in organization [33].

\section{B. Planning}

It is vital that business executives and IT people plan strategies with mutual consensus and coordination. Since business requirements and dynamics keep changing therefore change in strategy should be communicated to IT people so that underpinning technologies are aligned with the business requirements. This can be achieved when business strategic goals are well understood by business and IT people and their planning support business objectives. However, merely proper business and IT planning is insufficient and business-IT alignment can be achieved provided business and IT strategies have been propagated further down in organization [18]. An IT alignment planning connects the business strategic goals with IT strategies and resources [28].

\section{Resources}

Business-IT alignment perturbation depends on human and financial resources. A paucity in any of the resources may result in misalignment between both the entities. The quality of skilled IT staff is essentially required for proper communication with top management and for latest technologies [34]. At times available resources do not bring the desired results to the organization; then it is necessary to reallocate the resources and try to establish an alignment between business and IT. Being valuable resources to organization IT staff and business executives should have capability to configure and change resources to maintain alignment between business and IT.

\section{Technology}

Organizations find difficulties to align technologies with business strategies as the latter change more frequently. This creates a misalignment between business and IT as financial constraints do not allow to replace or to change in technology infrastructure. Technology infrastructure that consists of software, hardware, networking and telecommunication is considered as an essential factor to keep alignment between business and IT. For maintaining business-IT alignment organizations should demonstrate some mature IT governance [19].

As the new business models are developed in organizations new technologies are required to support such models. Business processes and supporting technologies need tight integration so that alignment between business and IT can be maintained.

\section{E. Communication}

Communication is used to bring business and IT into an alignment. Business executives should communicate any future business strategies to IT staff in order to get technology support for the required business processes. Researchers and practitioners consider communication as a main source of alignment between business and IT and suggest developing communication channels between both domains [17]. There should be a common means of communication among the stakeholders in order to prevent from any perturbation between the two entities. An effective communication is a tool for sharing knowledge in both the entities, i.e. people from business and information technology units should exchange domain knowledge in order to align both the domains [27].

\section{F. Change Management}

When an organization needs to make changes, business and IT executives make decisions based on their knowledge and experience, but some elements of both the entities may not be visible to them which can have an impact in result of their decisions. This change requires proper management in order to keep alignment between business and IT. It is important for organizations to adapt changes that may impact on different components of business and supporting technologies [29].

In order to know the level of alignment in organizations a financial institution in Saudi Arabia was selected in which different factors were evaluated. To collect data from different employees in the organization a survey instrument was developed and distributed to all levels.

\section{RESEARCH METHODOLOGY}

In this study, it was considered survey as an appropriate and useful tool for collecting data from different employees so that information can be extracted in the same manner [14]. In a pre-arranged meeting with the management of the institution, we explained the purpose of the study and spotted the target staff in different departments from lower to higher levels in different departments. A survey instrument was designed that comprised of questions mainly in view of the organizational factors that may perturb alignment between business and IT. There were 93 questionnaires distributed by emails and by hand to the identified and targeted people in the financial institution. In the following distribution of the surveys, we maintained a constant communication with the respondents and answered their queries at times.

\section{A. Data Collection}

There were 93 questionnaires distributed to the staff members and 74 complete questionnaires were received. After scrutiny, 67 questionnaires were found suitable for the study. The questionnaire was designed by giving two types of questions, i.e. (1) open end and (2) close end questions. In open end questions only demographic information was asked, i.e. name, department, designation, age, qualification and experience, whereas in close end questions 30 questions were asked based on the factors in organization that may perturb alignment in business and IT. In the questionnaire each 
question was measured on Likert's scale with these five options: (1) strongly agree -5 , (2) agree -4 , (3) neutral -3 , (4) disagree -2 , and (5) strongly disagree -1 .

It was expected that respondents would complete the questionnaire in all aspects by providing required information. Proper instructions were written on the cover page of the instrument. The 74 complete questionnaires were received but carefully checking disclosed that there were seven questionnaires in which some respondents had not given required answer. Some respondents could not complete demographic open end questions or wrongly entered information or left blank space. In extracting information from a survey it is important to have a reliable data. A data element is considered reliable when an item gives the same result from the same object [15]. Another aspect in a survey is consistency that shows consistency is the scale that is used to measure items [16]. To determine internal consistency we used Cronbach's coefficient and it was found that the value of coefficient alpha is greater than 0.69 .

Table 1 shows the list of items with the given expressions in the questionnaire that we intended to investigate

TABLE I. ORGANIZATIONAL FACTORS AND ITEMS IN THE QUESTIONNAIRE

\begin{tabular}{|c|c|c|}
\hline Factor & Item & Expression \\
\hline \multirow{3}{*}{ Communication } & CS & Executives in both business and IT always communicate with each other \\
\hline & BS & In order to prepare business strategies IT and business people communicate \\
\hline & ST & For implementing new technologies IT staff communicate with business executives \\
\hline \multirow{3}{*}{$\begin{array}{c}\text { Change } \\
\text { Management }\end{array}$} & ME & Before making a change the management invites and consults with employees \\
\hline & $\mathrm{OM}$ & Organization quickly moves from a position by implementing new system \\
\hline & OR & In result of organizational change the management strives for staff retention \\
\hline \multirow{3}{*}{ Planning } & GO & All employees are well informed of the firm's goals \\
\hline & $\mathrm{CR}$ & With the change in requirements business goals are reviewed \\
\hline & PS & Business strategies are designed with mutual consultation with IT and business people \\
\hline \multirow{3}{*}{ Resources } & IO & Our company has outsourced the IT functions \\
\hline & RS & Our firm shuffled resources once business requirement is changed \\
\hline & HS & We have enough human and financial resources \\
\hline \multirow{3}{*}{ Structure } & $\mathrm{DM}$ & Management takes decision for any change in business \\
\hline & MD & Management decision is propagated at all levels \\
\hline & ID & For effective decision making central information repository is helpful \\
\hline \multirow{3}{*}{ Technology } & $\mathrm{AC}$ & In result of a business change architecture of technology is changed \\
\hline & $\mathrm{PC}$ & Customers can access our products and services through internet \\
\hline & ED & Employees in our company use intranet for data access \\
\hline
\end{tabular}

The purpose of the survey was to collect information as much as possible. Usually business processes and supporting technologies are misaligned in financial institutions due to their dynamic business. Therefore, it was decided to conduct this study in such institution to know level of alignment between business and IT domains. As the Table 1 shows different factors it is clear that we intended to obtain information from staff at various levels which may give clear picture of the institution. The open end questions were designed to know the background of respondents and the close end questions aimed to knowing their working environment and views based on different factors. It was observed that the staff members of the institution were excited in participation of the survey and some of them kept a constant communication throughout the survey and prompted queries and clarified any ambiguity they had. The management of the institution showed an interest in finding out the results of the survey in order to know the level of alignment in the organization.

\section{B. Data Analysis}

The data collected from the questionnaire were entered into an excel spreadsheet with the codes as stated earlier as "strongly agree" with 5, "agree" with 4 and so on. Table 2 shows the items and the responses received. 
TABLE II. ORGANIZATIONAL ITEMS AND RESPONSES

\begin{tabular}{|c|c|c|c|c|c|c|}
\hline \multirow[b]{2}{*}{ Item } & \multicolumn{5}{|l|}{ Response } & \multirow[b]{2}{*}{ Score } \\
\hline & Strongly agree & Agree & Neutral & Disagree & $\begin{array}{l}\text { Strongly } \\
\text { disagree }\end{array}$ & \\
\hline$\overline{D M}$ & 28 & 22 & 5 & 8 & 4 & 3.92 \\
\hline MD & 12 & 15 & 3 & 22 & 15 & 2.83 \\
\hline ID & 10 & 17 & 5 & 23 & 12 & 3.08 \\
\hline GO & 14 & 20 & 5 & 16 & 12 & 3.11 \\
\hline $\mathrm{CR}$ & 20 & 24 & 5 & 12 & 6 & 3.80 \\
\hline PS & 10 & 8 & 5 & 16 & 14 & 2.13 \\
\hline $\mathrm{IO}$ & 19 & 23 & 4 & 15 & 6 & 3.50 \\
\hline $\mathrm{RS}$ & 22 & 26 & 7 & 8 & 4 & 3.65 \\
\hline HS & 8 & 10 & 5 & 30 & 14 & 2.52 \\
\hline$\overline{\mathrm{AC}}$ & 8 & 13 & 6 & 27 & 13 & 2.64 \\
\hline $\mathrm{PC}$ & 29 & 20 & 6 & 8 & 4 & 3.92 \\
\hline ED & 21 & 27 & 4 & 9 & 6 & 3.71 \\
\hline $\mathrm{CS}$ & 11 & 15 & 5 & 30 & 6 & 2.92 \\
\hline BS & 8 & 14 & 5 & 27 & 11 & 2.62 \\
\hline ST & 8 & 11 & 3 & 26 & 19 & 2.44 \\
\hline $\mathrm{ME}$ & 13 & 15 & 4 & 22 & 11 & 2.86 \\
\hline $\mathrm{OM}$ & 7 & 15 & 5 & 24 & 16 & 2.59 \\
\hline OR & 19 & 25 & 4 & 13 & 6 & 3.56 \\
\hline
\end{tabular}

Total score of each item was calculated in which respondents opted from strongly agreed to strongly disagreed. The Figure 1 shows each item with the respective total score.

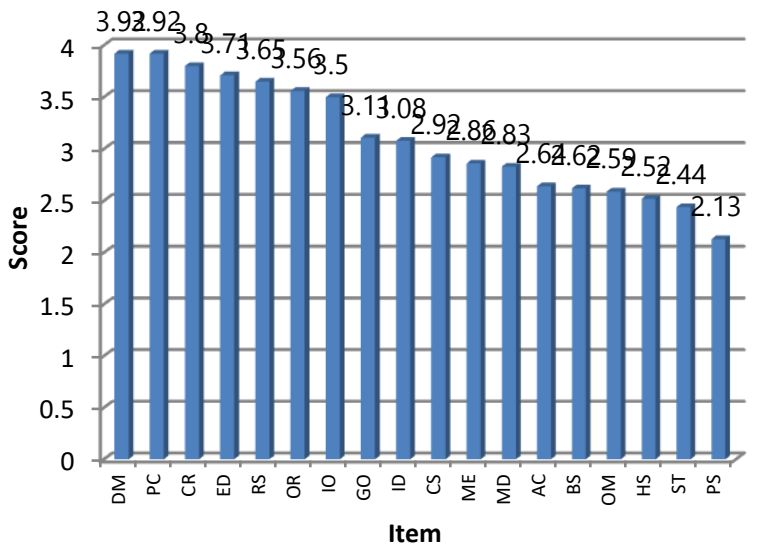

Fig. 1. Organizational items scores

\section{RESULTS AND DISCUSSION}

It is evident from the Figure 1 that the institution under study takes decision at the upper level as the item DM is one of the items who has received the highest score from the staff members. The score shows that decisions made by the management are not propagated properly at the lower levels as the score of item MD also depicts the fact. The items BS, CS and ST are from communication factor which shows that there is no proper communication among business executives and IT personnel within the organization. This results in perturbation of business and IT and misalignment occurs.

The data shows the lack of communication among the members of the organization and as the item PS depicts during formulation of business strategies IT personnel are not taken into confidence and hence, the planning factor causes a perturbation in the business-IT alignment in the organization.
Also it is evident from the data that staff members at the lower levels do not get benefit from the centralised information for decision making. The score of item ID supports this statement. It is to be noted from AC item score that when a business change is implemented in organization the technology architecture remains intact, i.e. architecture is not changed due to a change in business requirement. The institution, however, checks the available resources and in result of a business change resources are rearranged as the item RS depicts by its score. This also shows the rearranging resources means new resources are not acquired and integrated in the institution. The scores of items HS and ST show that human resources are enough in the institution but they are not being utilised effectively; similarly technical personnel do not communicate with business people before implementing new technologies.

This study presents a number of critical factors that organizations have to consider for business-IT alignment. Specifically communication factor plays a vital role as this tool can be used at every level in organization to disseminate strategies required to bring a change in business. As the organizations are moving towards decentralisation we recommend centralisation be removed in order to get better alignment between business and IT. This study is limited to one financial institution but in future other organizations can be considered to study the stated factors in order to determine business-IT alignment.

In future, this study can be enhanced to other organizations where organizational hierarchy is complex and decision making is centralised. There are other factors that may perturb business-IT alignment and other researchers may explore such factors.

\section{REFERENCES}

[1] J. Henderson, and N. Venkatraman, "Strategic alignment: analysis of information technology for transforming organizations", IBM Systems Journal, vol. 32, pp. 472-484, 1993

[2] J. Luftman, "Competing in the information age: practical applications of the strategic alignment model", Oxford University Press, 1996, New York.

[3] E. Chan, "Why haven't we mastered alignment? The importance of the informal organization structure", MIS Quarterly Executive, vol. 1, pp. $97-112,2002$ 
[4] M. Mohamed., R. Lazar., and P. Erik., "From theory to practice: Barriers to business-IT alignment in organizaions acting in Sweden", 48th Hawaii International Conference on System Sciences, pp. 4523-4533, 2015

[5] T. Aymen, Z. Mohamed, and K. Mumtaz."Factors influencing the adoption of IT projects: A proposed model", in proceedings of 2008 IEEE International Symposium on IT in Medicine and Education, pp. 1019-1023, 2008

[6] [6] S. Bruque, and J. Moyano, "Organizational determinants of information technology adoption and implementation in SMEs: The case of family and cooperative firms", Technovation, vol. 27, pp. 241-253, 2007

[7] A. Akbulut, "An investigation of the factors that influence electronic information sharing between state and local agencies", Eighth Americas Conference on Information Systems, pp. 2454-2460, 2002

[8] L. Chuck, N. Eric, "IT Infrastructure Capabilities and Business Process Improvement: Association with IT Governance Characteristics", Information Resources Management Journal, vol. 20, pp. 25-47, 2007

[9] S. Sam, B. Harry, I. Timo, "Networked enterprise business model alignment: A case study of smart living", Information System Frontier, vol. 17 , pp. 871-887, 2015

[10] V. Iris, and W. Kerry, "The dynamics of sustaibable alignment: The case of IS adaptivity", Journal of Association for Information systems, vol. 14 , pp. 283-311, 2013

[11] H. Hui-Ling, "Performance effects of aligning service innovation and the strategic use of information technology", Service Business, vol. 8,pp. 171-195, 2014

[12] C. Suwatana, W. Winai, and K. Do Ba, "Business-IT alignment: A practical research approach", Journal of Higher Technology Management Research, vol. 25, pp. 132-147, 2014

[13] L. Runyan, "Borderless Banking Draws IS interest, Datamation", pp. 98100, 1990

[14] M. Saunders, P. Lewis and A. Thornhill, "Rsearch nethods for business students", 3rd ed. Prentice Hall

[15] E. Carmines, R. Zeller, "Reliability and Validity Assessment, 1979, SAGE Publications

[16] J. Cronbach, "Coefficient alpha and the internal structure of tests", Psychometrika, vol. 16, pp. 297-334, 1951

[17] O. Fonstad, and D. Robertson., "Transforming a company, project by project: the IT engagement model", MIS Quarterly Executive, vol. 5, pp. $1-14,2009$

[18] E. Nfuka, and L. Rusu, "Critical success factors for effective IT governance in the public sector organizations in a developing country: The caseof Tanzania", 18th European Conference on Information Systems, 2010, South Africa

[19] S. Haes, and W. Grembergen, "Exploring the Relationship between IT Governance Practices and Business/IT alignment through Extrteme Case Analysis in Belgian mid-to-large Size Financial Enterprises", Journal of Enterprise Information Management 22, pp. 615-637, 2009

[20] R. Grant, "Contemporary strategy analysis", 5th ed. Blackwell Publishing: Malden, 2005, USA

[21] N. Melville, K. Kraemer, and V. Gurbaxani, "Review: Information technology and organisational performance: An integrative model of IT business value", MIS Quarterly, vol. 28, pp. 283- 322, 2004

[22] E.Brynjolfsson, "The IT productivity gap", Optimize, pp. 26-43, 2003

[23] M. Khan., "An Integrated Framework to Bridging the Gap between Business and Information Technology - A Co-evolutionary Approach", Canadian Journal of Pure and Applied Sciences, 7(3), pp. 2611-2618, 2013

[24] K. Albeladi, U. Khan, and M. Khan, "Driving Business Value through an Effective IT Strategy Development", in Proceedings of International Conference on Computing for Sustainable Global Development, pp.561563,2014

[25] L. Aversano, C. Grasso, and M. Tortorella, "Managing the Alignment between Business Processes and Software Systems", Information and Software Technology, vol. 72, pp. 171-188, 2016

[26] E. Seman, and J. Salim, “A Model for Business-IT Alignment in Malaysian Public Universities", Procedia Technology, vol. 11, pp. 11351141,2013

[27] S. Charoensuk, W. Wongsurawat, and D. Khang, "Business-IT alignment - A practical research Approach", Journal of High Technology Management Research, vol. 25, pp. 132-147, 2014

[28] D. Peak, C. Guynes, V. Prybutok, \& C. Xu, "Aligning Information Technology with Business Strategy: An Action Research Approach", Journal of Information Technology Case and Application Research, vol. 13, pp.13-42, 2011

[29] O. Avila, and K. Garcés, "Change Management Contributions for Business-IT Alignment. In: Abramowicz W., Kokkinaki A. (eds) Business Information Systems Workshops. BIS 2014", Lecture Notes in Business Information Processing, vol. 183, 2014

[30] F. Fattah, and A. Arman, "Business-IT Alignment: Strategic Alignment Model for Healthcare (Case Study in Hospital Bandung Area)", in Proceedings of International Conference on ICT for Smart Society, pp. 256-259, 2014

[31] H. Knut, and P. Alex, "Supporting business and IT alignment by modeling business and IT strategy and its relation to enterprise architecture", in proceedings of Second International Conference on Enterprise Systems, pp.149-154, 2014

[32] H. Aggarwal, "Critical success factors in IT alignment in public sector petrolium industry in India", International Journal of Innovation, Management and Technology, vol. 1, pp. 56-63, 2010

[33] K. Ilir, B. Ezmolda, and S. Kozeta, "Critical success factors for business - it alignment: a review of current research", Romanian Economic and Business Review, vol. 8, pp. 79-97, 2013

[34] P. Poon, and C. Wagner, "Critical success factors revisited: success and failure cases of information systems for senior executives", Decision Support Systems, vol. 30, p. 393-418, 2001

[35] M. Khan, "Understanding a Co-evolution Model of Business and IT for Dynamic Business Process Requirements", International Journal of Advanced Computer Science and Applications, vol. 7, pp. 348-352, 2016

[36] W. Heinz-theo, and J. Moshtaf, "Individual IT roles in business-IT alignment and IT governance", in proceedings of 49th Hawaii International Conference on System Sciences, pp. 4920-4929, 2016 